\title{
Colonic Stenting Using Side-Viewing Endoscope: A Case Report
}

\author{
Ashok Dalal ${ }^{1}$ Ajay Kumar ${ }^{1} \quad$ K Arivarasan $^{1} \quad$ Amol Dahale $^{1}$ Sanjeev Sachdeva ${ }^{1}$ Ujjwal Sonika ${ }^{1}$ \\ Ankush Pawar ${ }^{1}$ \\ ${ }^{1}$ Department of Gastroenterology, GB Pant Hospital, New Delhi, India \\ J Digest Endosc 2021;12:247-248. \\ Address for correspondence Dr. Ashok Dalal, MD, DM, Department of \\ Gastroenterology, GB Pant Hospital, Academic Block, 1, JLN Marg, \\ New Delhi 110002, India (e-mail: drashokdalal83@gmail.com).
}

\author{
Abstract \\ Keywords \\ - colonic stenting \\ - colonic obstruction \\ - side viewing \\ endoscope
}

Colonic self-expandable metal stents (SEMS) are widely used as palliation for malignant obstruction. The conventional method involves using a forward-viewing endoscope as part of the procedure. Sometimes, however, the sharp angle of the stricture poses difficulty in evaluating the stricture, so a guidewire is placed across the stricture. Here, we present a case where a side-viewing endoscope was employed for colonic stent placement and propose its use in patients with sharp bends to increase success.

\section{Introduction}

Colonic stenting has been accepted as an alternative to surgery for palliation or bridge to surgery for patients with colorectal cancers, presenting with complete large bowel obstruction. Various techniques have been proposed for the placement of the self-expanding metallic stent (SEMS). ${ }^{1}$ Sharp angulation and tortuous bends in the colon pose difficulty in placement of the SEMS. Previously, a single case report had been published on the use of the sideviewing endoscope for placement of SEMS in colon. ${ }^{2}$ Here, we present our experience of one such case in which we have used the side-view endoscope for placement of SEMS in colon.

\section{Case}

A 56-year-old gentleman presented with acute complete large intestinal obstruction for the last 8 days. The patient also had history of loss of appetite and significant weight loss over the last 3 months. Abdominal X-ray showed multiple airâ fluid levels. CT revealed short segment stricture with mural thickening at the sigmoid and descending colon junction; also, a space-occupying lesion (SOL) in the liver, suggestive of a metastatic lesion. Fine needle aspiration from liver SOL showed metastatic adenocarcinoma. The patient was not fit for surgery in view of poor performance status and was referred for palliative stenting. A lower gastrointestinal (GI) endoscopy was planned, and the patient was prepared by giving him a proctoclysis enema. On lower GI, a $3 \tilde{A} 3 \mathrm{~cm}$ proliferative growth was seen at the distal sigmoid colon which was easily negotiable, and another concentric growth was seen at the junction of sigmoid and descending colon. This growth was at a sharp angle, occluding the lumen completely. This sharp angulation at the sigmoid-descending colon junction created difficulty in assessment of the stricture and passage of guidewire across using the conventional forward viewing colonoscope, even after changing the position of the patient. Hence, using a standard side-viewing endoscope was considered, and it provided optimal visualization of the stricture in right lateral position. Using a standard sphincterotome (Boston Ultratome $\mathrm{XL}, 5 \mathrm{fr}$ ), the stricture was negotiated and hybrid guidewire (0.035 in, $450 \mathrm{~cm}$ Jagwire, Boston Scientific, USA.) was placed across the stricture into proximal colon under fluoroscopic guidance. With the guidewire in position, contrast (Urograffin $20 \%$ ) was injected to confirm that guidewire has been placed
DOI https://doi.org/ 10.1055/s-0040-1713833. ISSN 0976-5042. (c) 2022. Society of Gastrointestinal Endoscopy of India. All rights reserved.

This is an open access article published by Thieme under the terms of the Creative Commons Attribution-NonDerivative-NonCommercial-License, permitting copying and reproduction so long as the original work is given appropriate credit. Contents may not be used for commercial purposes, or adapted, remixed, transformed or built upon. (https://creativecommons.org/ licenses/by-nc-nd/4.0/)

Thieme Medical and Scientific Publishers Pvt. Ltd., A-12, 2nd Floor, Sector 2, Noida-201301 UP, India 


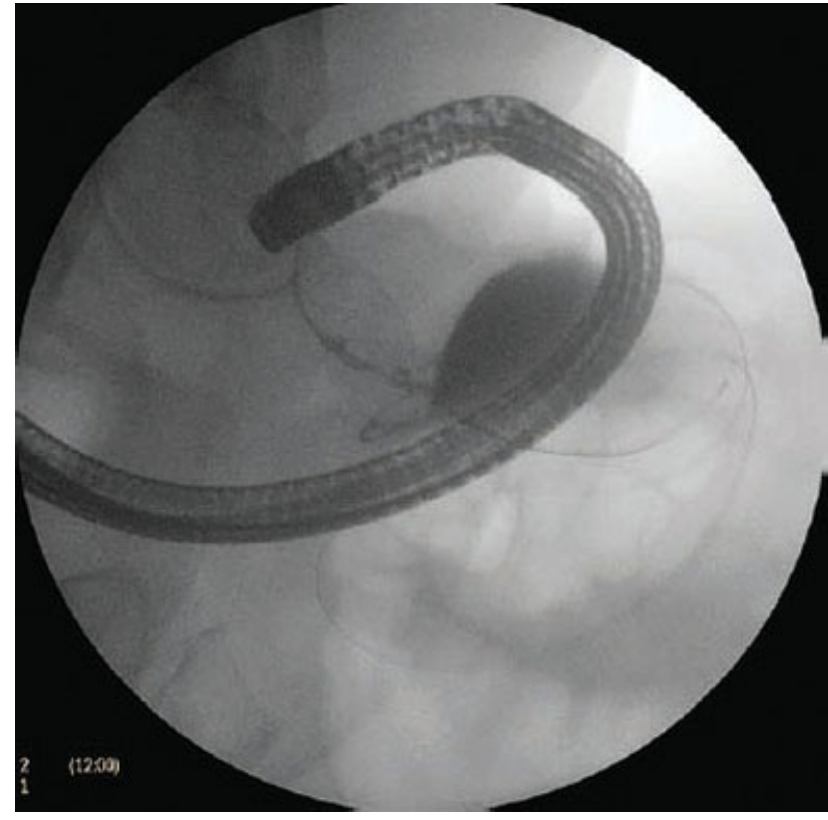

Fig. 1 Fluoroscopic image showing SVE (side viewing endoscope)-assisted wire placement across stricture and assessment of stricture length.

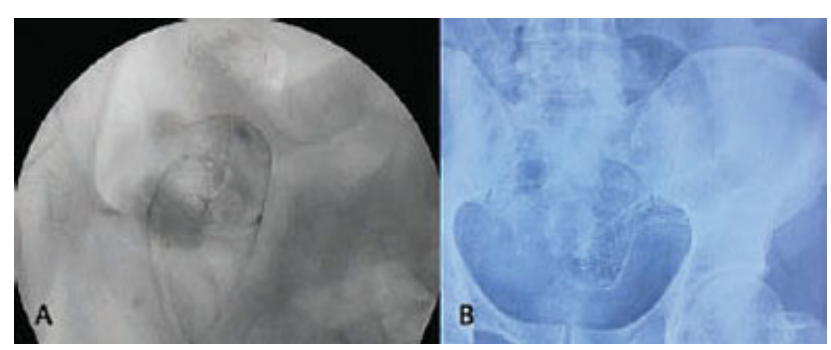

Fig. 2 (A) Fluoroscopic image after stent placement. (B) X-ray showing stent waist and straightening of stent.

across the stricture in proximal colon and length of the stricture was assessed to be approximately $3 \mathrm{~cm}$ (-Fig. 1). Subsequently, an uncovered SEMS $(22 \mathrm{~mm} * 100 \mathrm{~mm}$ Bonastent) was placed across the stricture under combined endoscopic and fluoroscopic guidance (-Fig. 2). Immediately after, the successful deployment of SEMS stool was seen coming out of the distal end of SEMS. The patient was placed on liquid diet and given osmotic laxatives over the next 3 days. He purged a lot, and on day 3, there was complete resolution of symptoms. Repeat X-ray abdomen done on day 3 showed stent in position (-Fig. 2) with resolution of bowel obstruction. The stent, which was showing an acute angle after placement on fluoroscopy, was now straightened up, showing a waist. We attribute this effect to fecal-loaded colon, exaggerating the acute angulation of sigmoid and
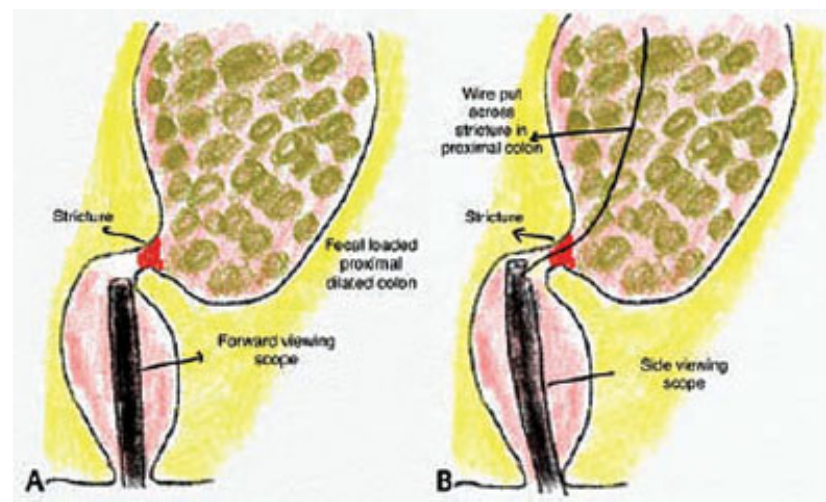

Fig. 3 (A) Schematic diagram of stricture assessment using forward viewing scope. (B) Stricture assessment using side-viewing scope.

descending colon junction due to the pressure effect. After the relief of obstruction, this pressure effect was relieved, and the junction straightened up.

\section{Discussion}

Optimal visualization of the colonic stricture during the placement of the SEMS improves the technical success and prevents undue complication in already moribund patients. Sharp angulations in the colon present a difficulty in optimal evaluation and placement of the SEMS across the stricture using standing flexible lower GI endoscope. So, we propose the use of side-viewing endoscope in cases where sharp angulation pose problems to visualization (-Fig. 3 ).

\section{Sources of Support \\ None declared.}

\section{Disclosure of Funding \\ None.}

\section{Conflicts of Interest}

None declared.

\section{References}

1 van Hooft J E, van Halsema E E, Vanbiervliet G, et al. European Society of Gastrointestinal Endoscopy. Self-expandable metal stents for obstructing colonic and extracolonic cancer: European Society of Gastrointestinal Endoscopy (ESGE) Clinical Guideline. Endoscopy 2014;46(11):990-1053

2 Cennamo V, Fuccio L, Laterza L, et al. Side-viewing endoscope for colonic self-expandable metal stenting in patients with malignant colonic obstruction. Eur J Gastroenterol Hepatol 2009;21(05): 585-586 